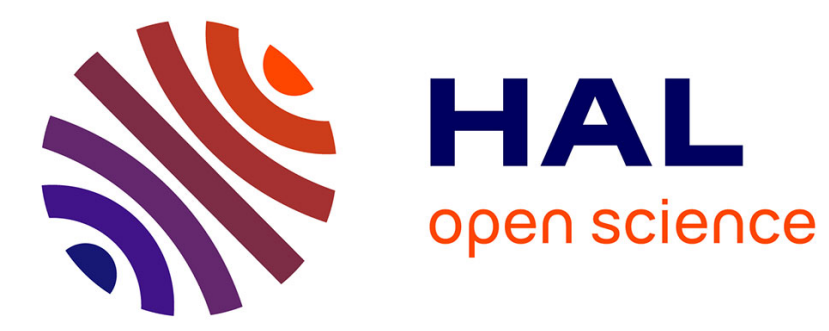

\title{
Evaluation of drilling parameters of a PDC bit
}

\author{
H. Geoffroy, D. Nguyen Minh, Habibou Maitournam, J. Bergues, C. Putot
}

\section{To cite this version:}

H. Geoffroy, D. Nguyen Minh, Habibou Maitournam, J. Bergues, C. Putot. Evaluation of drilling parameters of a PDC bit. Advances in Rock Mechanics, 35, pp.578-580, 1998, 10.1142/9789812839640_0028. hal-00111605

\section{HAL Id: hal-00111605 https://hal.science/hal-00111605}

Submitted on 10 Sep 2019

HAL is a multi-disciplinary open access archive for the deposit and dissemination of scientific research documents, whether they are published or not. The documents may come from teaching and research institutions in France or abroad, or from public or private research centers.
L'archive ouverte pluridisciplinaire HAL, est destinée au dépôt et à la diffusion de documents scientifiques de niveau recherche, publiés ou non, émanant des établissements d'enseignement et de recherche français ou étrangers, des laboratoires publics ou privés. 


\author{
H. GEOFFROY ${ }^{a}$, D. NGUYEN MINH, H. MAITOURNAM, J. BERGUES \\ LMS-Ecole Polytechnique, \\ 91128 Palaiseau, France \\ E-mail: duc@athena.polytechnique.fr \\ C. PUTOT \\ IFP, 3-4 Avenue Bois-Préau, \\ 92506 Rueil-Malmaison, France \\ E-mail: claude.putot@ifp.fr
}

\begin{abstract}
A drilling model for PDC bit is presented herein within steady bit advance hypothesis, with taking into account influence of wear and its evolution. First, friction mechanism on cutter wear flats, is studied by experimental and numerical approach. It is shown to correspond to a relationship between the normal applied pressure to the cutter wear flat, and its subsequent dip angle $\alpha$ into the rock surface. It is shown that frictional wear is directly influenced by bit profile. Typical results are exhibited for elliptic profiles and compared with literature.
\end{abstract}

\title{
1 Introduction
}

Polycrystalline Diamond Compact (PDC) bits were introduced in petroleum industry in the early 1970's. A PDC bit is composed of a multiplicity of individual cutters mounted on the surface of the bit body (Figure 1). The high rate of penetration $(R O P)$ of these bits is due to shearing action of cutters instead of crushing, producing faster penetration rates with less weight on bit $(W O B)$ than roller cone bits. A sharp PDC bit will typically drill two to three times faster than the best tricone in soft formations, but such performance will gradually decrease with increasing wear.

In normal drilling conditions, e.g. under moderate temperature condition not exceeding $350^{\circ} \mathrm{C}$, abrasion is the main cause of wear, resulting in growth of a wear flat on the cutter base $\left(\right.$ Glowka $\left.^{2}\right)$. Friction on wear flat can dissipate up to $50 \%$ of the total energy for drilling. For this reason, a better understanding of bit performance has to consider the worn tool. Although many studies have dealt with this subject in literature, the frictional mechanism generated by wear on cutters has still been overlooked.

This study is devoted to model the frictional mechanism on a single worn cutter in relation with rheology of the rock, in order to integrate it in a global drilling model. Illustrative examples are given for some bit geometries.

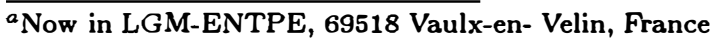




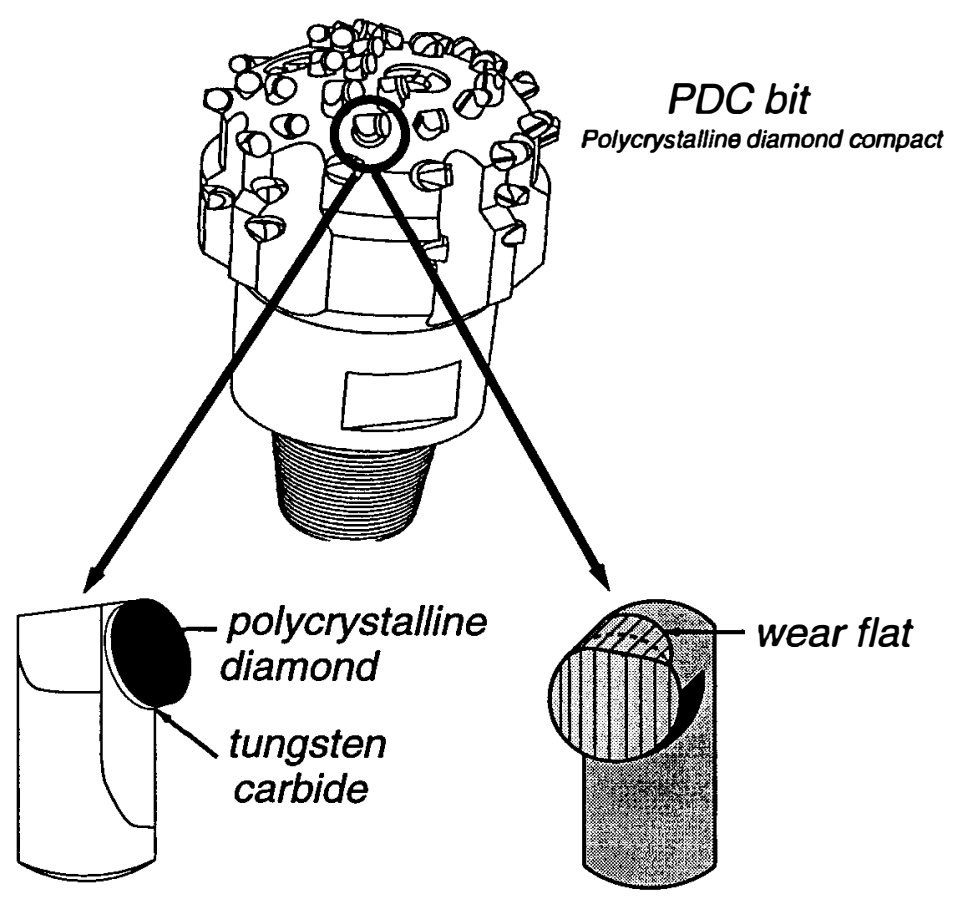

Figure 1: A PDC bit

\section{Mechanisms involved by a worn PDC cutter}

A cutter model with wear flat is shown on Figure 2. Let $n$ and $t$ be the local cutter axes in a plane containing the displacement vector of the cutter, and normal to the wear flat. The forces applied to the cutter are usually considered to share into two forces related to independent mechanisms: cutting force on the cutting face (superscript $c$ ), and a frictional one on the wear flat (superscript $f$ ) (Detournay ${ }^{3}$, Sellami ${ }^{4}$, Kur ${ }^{5}$, Nguyen Minh ${ }^{6}$ ). Their coordinates in $(n, t)$ plane (subscript $n, t)$ are :

$$
F_{t}=F_{t}^{c}+F_{t}^{f} \text { and } F_{n}=F_{n}^{c}+F_{n}^{f}
$$

Nguyen Minh ${ }^{6}$, Sellami ${ }^{4}$ considered cutting as a yield load mechanism. Indeed, this concept is somehow equivalent to specific energy one $\epsilon_{0}$ (Detournay ${ }^{3}$, Kuru ${ }^{5}$ ), defined as the amount of energy to remove a unit volume of rock, with 


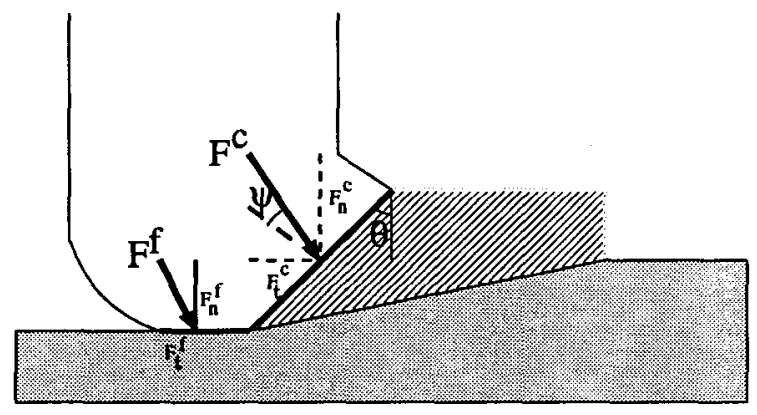

Figure 2: Forces acting on the worn cutter.

$\epsilon_{0}$ of the order of the rock compressive strength in atmospheric conditions. We have :

$$
F_{t}^{c}=\epsilon_{0} A_{c} \text { and } F_{n}^{c}=\zeta F_{t}^{c}
$$

$A_{c}$ is the cross-sectional area swept the cutter in its movement. $\zeta$ is given by $\zeta=\tan (\theta+\psi) . \theta$ is the back rake angle and $\psi$ the interface friction angle.

Things are not so clear for the frictional mechanism. Kurư ${ }^{5}$, sets the mean normal pressure on wear flat to point load strength, Sellami ${ }^{4}$ to the normal cutting stresses, and Detournay to the uniaxial compressive strength.

Alternatively, on the basis of experimental observations, Nguyen Minh ${ }^{6}$, proposes a mechanism related to elastoplastic deformations. The author performed drag tests on a flat based cutter on a model material standing for a plastic rock (sand mixed with paraffin). The cutter penetrates into the horizontal rock surface with a dip angle $\alpha$, increasing with the normal applied load unless the surface bearing capacity of the sample is exceeded. This behaviour would fully represent the friction mechanism on the wear flat, but needs to be verified, namely by experimental confirmation on actual rocks and by numerical validation.

This is the first objective this study, which aims at finding out, for a given elastoplastic rock behaviour, a relationship between $\alpha$ and the applied forces on the wear flat. For a flat nose bit, with cutter wear flats parallel to bottom face, angle $\alpha$ represents the dip angle of the helical trajectory of each cutter (Figure 3).

With a typical penetration rate ranging from $15 \mathrm{~m} / \mathrm{h}$ to $60 \mathrm{~m} / \mathrm{h}$, and average $120 \mathrm{rev} / \mathrm{mn}$ rotary speed, penetration per revolution $\delta$ range from 2 to 8 $\mathrm{mm}$. So, for a $216 \mathrm{~mm}$ diameter bit, we have typically $3.10^{-3}<\tan \alpha<6.10^{-2}$ 


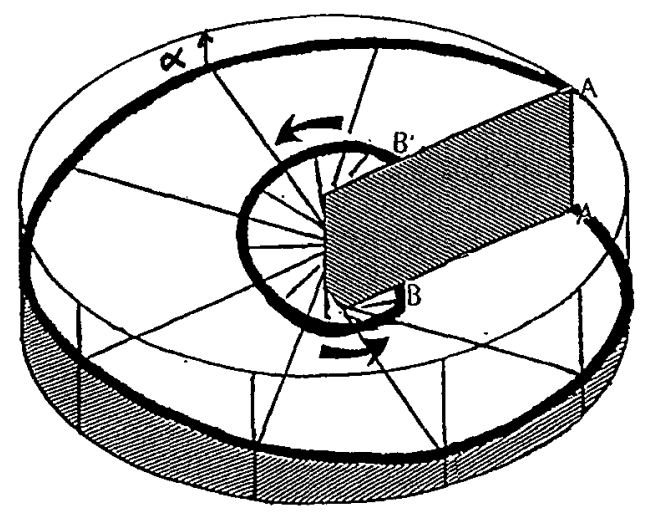

Figure 3: helical trajectory of a cutter on a flat nose bit, and $\alpha$ angle

\section{Study of the frictional mechanism}

\subsection{Experimental analysis}

In order focus on parameter $\alpha$, tests were performed with constant normal applied load (Figure 4). With regard to the small $\alpha$ angle involved, it would not be possible to run classical tests with constant depth of cut. A circular sample is rotated by an electric motor, allowing measurement of an average penetration slope of the cutter on a great distance, e.g. on several rounds. The cutter is mounted on a ram fixed on a rigid frame. The ram can be placed at different radii in order to simulate different cutter positions on the bit. Forces applied on the cutter are recorded by a three dimensional piezoelectric force gage, and depth of penetration by LVDT. The rock tested is a chalk from Liege (Belgium). Its complex behaviour exhibits important plastic deformations due to the gradual breakage of the porous structure, both under hydrostatic and deviatoric loadings. This rock was selected because of its good homogeneity and small grain size, and its low strength.

Two different tests were performed with iron cutter models, one with a sharp circular cylinder with back rake angle $20^{\circ}$ and $13 \mathrm{~mm}$ diameter, to identify cutting mechanism, the other with a flat based parallelepiped $10 \mathrm{~mm}$ long, $3 \mathrm{~mm}$ large and $6 \mathrm{~mm}$ thick with $0^{\circ}$ rake angle $\theta$ to enhance friction mechanism. (Geoffroy ${ }^{7}$ ). Depth of cut $(d)$ versus displacement of the cutter 


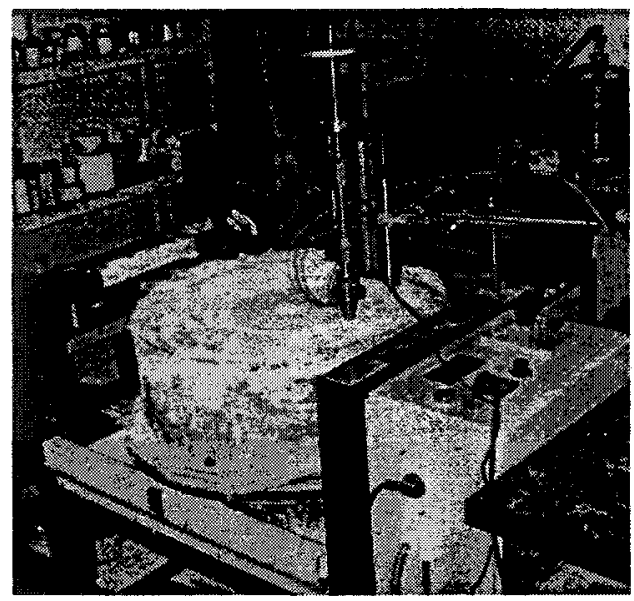

Figure 4: Testing apparatus

a)

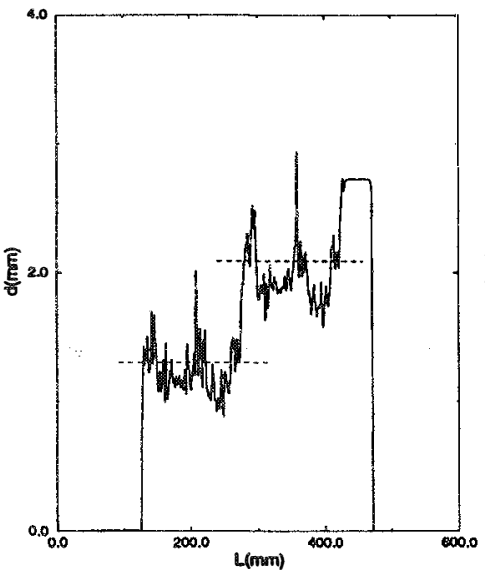

b)

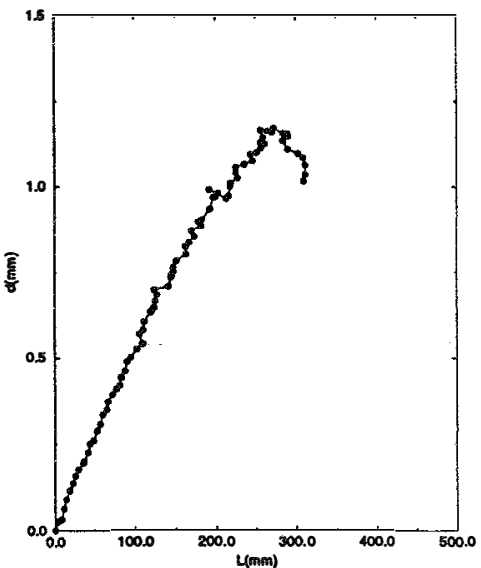

Figure 5: Depth of penetration $d$ versus distance $L$. a) Cutting mechanism, b) Frictional mechanism 
$(L)$ curves show the difference between the two mechanisms (Figure 5). The sharp cutter stabilizes rapidly to a definite depth, whereas the flat based parallelepiped penetrates gradually into the rock with a mean dip angle $\alpha$, which has to be related to the mean applied normal stress.

\subsection{Numerical analysis of the frictional mechanism}

\section{Formulation}

Within the hypothesis of two independent mechanisms of the worn tool - cutting and friction - the frictional contact between the cutter wear flat and the rock can be idealised by a plane strain problem, with a constant velocity moving rigid slider inclined by angle $\alpha$ on the surface of a half plane (Figure 6).

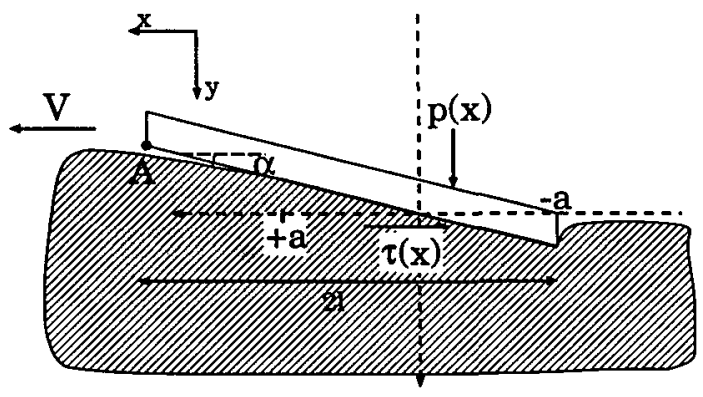

Figure 6: Wear flat model

This is a frictional unilateral contact problem, with unknown contact length $2 a$, normal pressure condition $p(x) \geq 0$ and shear stress related to normal pressure by a Coulomb's law $\tau(x)=\mu p(x)$ on contact area $[-a, a]$. This problem is resolved by means of an algorithm of contact described in more details in (Geoffroy ${ }^{7}$ ). It has been validated, using an analytical elastic solution of this problem $\left(\right.$ Adachi $\left.^{8}\right)$ :

The steady motion of the slider is simulated, using a specific steady algorithm in plane strain finite element code. This algorithm allows, in a reference moving with the cutter, to treat the stationary problem on a fixed geometry (Maitournam $^{9}$ ).

Two models were used to describe elastoplastic rock mass behaviour.

A Von Mises law, as a perfect elastoplastic model, is intended to confirm the $\alpha$ vs $F_{n}^{f}$ relationship revealed by tests, and to verify whether the "frictional mechanism" may be related to a deformation of elastoplastic type, and to show how transition to the limit point load occurs. 


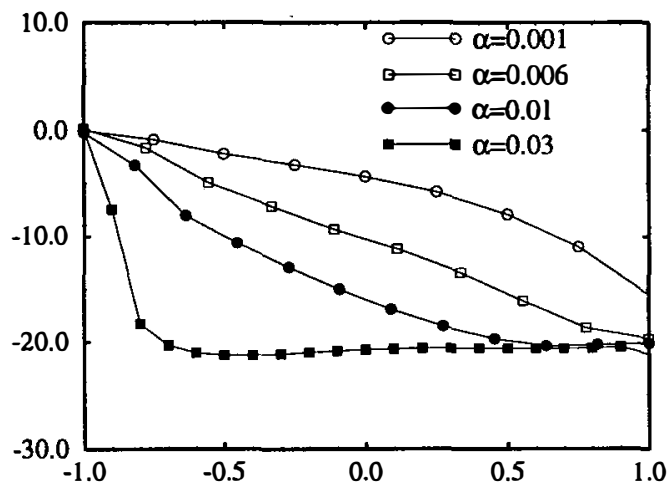

Figure 7: Evolution of the distribution of normal pressure beneath the punch for different values of penetration angle $\alpha$.

A Cam-Clay model precises the plastic volumetric strains inside the rock medium, taking into account strain hardening and softening, pressure dependency, dilatancy and pore collapse of chalk.

Indeed, an approximate solution of the frictional problem is obtained in two steps. First, the smooth slider is considered, $2 a$ and $p(x)$ are calculated for a prescribed $\alpha$ angle $\left(10^{-3} \leq \alpha \leq 5.10^{-2}\right.$ rd). Then, for the frictional case $(\mu=0.5)$, pressure distribution $p(x)$ already obtained in the former calculation and a shear stress distribution $\tau(x)=\mu p(x)$ are prescribed on the contact length $2 a$, so that a mean $\alpha$ angle can be evaluated.

\section{Numerical simulation data}

Let $P$ be the mean normal pressure on the slider contact area.

With Von Mises model, $P$ initially increases with $\alpha$ until $2.10^{-2} \mathrm{rad}$, then reaches a stationary value, which appears to be close to the theoretical bearing capacity of a flat punch (Figure 8). In the same way, as $\alpha$ increases, the distribution of normal pressure $p(x)$ under the punch tends towards a uniform distribution when limit point load is approached (Figure 7).

But, with Cam-Clay model, $P$ increases continuously, due to strain hardening, and an ultimate bearing capacity does not appear in this case. For a 


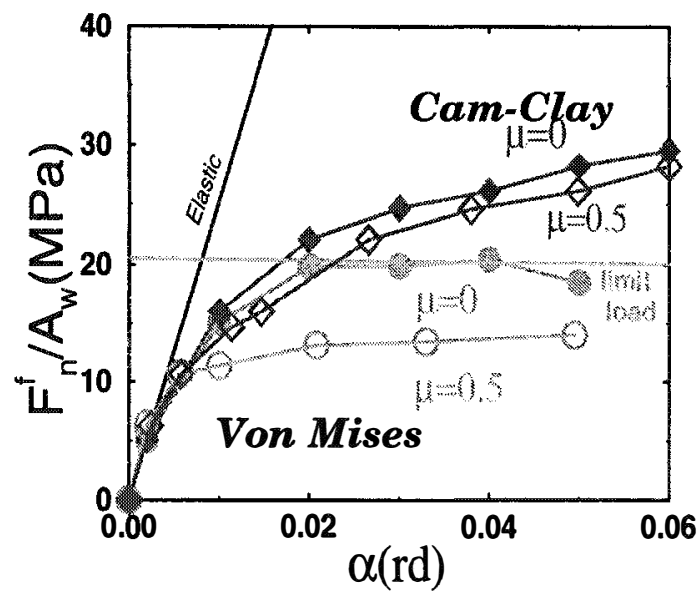

Figure 8: $P_{0}(M P a)$ versus $\alpha:$ Von Mises and Cam-Clay laws

given mean applied normal stress $P, \alpha$ is larger if friction increases.

Plastic volumetric strains under the slider have been represented for Cam-Clay law in the smooth slider case (Figure 9). Contractant zones appear beneath the punch (pale zone, water drop shape). Behind the punch, near the surface, a thin contractant zone appears too, overlying a more important dilatant region in the rockmass (dark zone) . However, with frictional contact, all the domain turns to be contractant.

\subsection{Conclusion}

We have shown that friction mechanism on cutter wear flat can be understood as an elastoplastic driven mechanism which expresses as a relationship $P=$ $f(\alpha)$ between the mean applied normal pressure $P$ on the wear flat surface, and its subsequent dip angle $\alpha$. This angle will be locally determined by the movement of the wear flat relative to rock surface. To sum up, simplified forms can be proposed, which take into account an eventual existence of a limit load $\sigma_{0}$ :

$$
f(\alpha)=\sigma_{0}\left(1-\exp \left(-\alpha / \alpha_{0}\right)\right) \text { if a limit point load exists }
$$




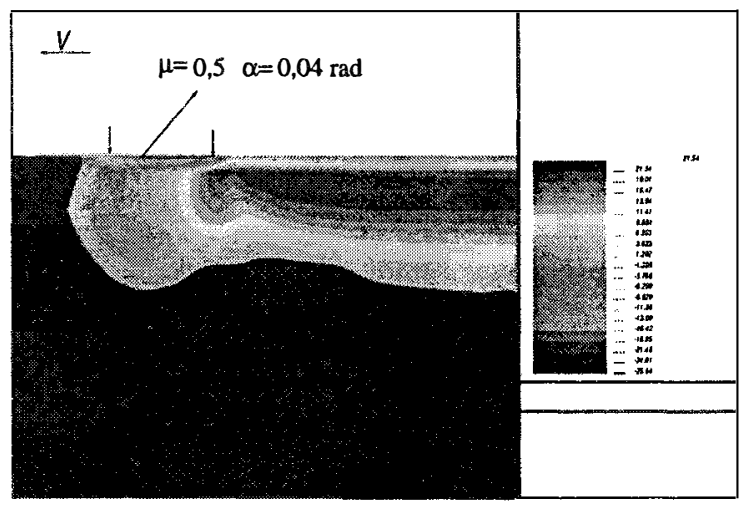

Figure 9: Cam-Clay law ; plastic volumetric zones ; $\mu=0.5 ; \alpha=0.05$ rd

$$
f(\alpha)=\sigma_{0}\left(1+\beta_{0} \alpha-\exp \left(-\alpha / \alpha_{0}\right)\right) \text { otherwise }
$$

The parameters are function of the rheology of the rock and could be obtained numerically or experimentally. Remark that the slope at the origin is related to elasticity and should be proportional to the elastic modulous $\left(\right.$ Adachi $\left.^{8}\right)$, which should imply a relationship between $\sigma_{0}, \alpha_{0}, \beta_{0}$. Indeed such a relationship has to be ignored with such a simple formulation.

\section{A drill bit model}

It is now possible to propose a drill bit model with taking into account wear effect and wear evolution, provided a relevant wear law be choosen. The geometry of the bit has first to be precised.

\section{1 geometry of the bit}

Let us define the bit profile (curve $z(y)$ ), as the locus of all the PDC centres when projected on a same fixed meridian plane $(y, z)$, moving along with the bit on direction $z$ (Figure 10). This profile is supposed to be a smooth curve $z(y)$. A cutter on the bit is then defined by a point on the bit profile and its angular position $\theta$. The bit is supposed to proceed steadily, with constant rotation and advance rate.

As no viscous effects or cutting evacuation problem is considered herein, the movement of the bit can be simply described by its depth of penetration $\delta$ per revolution in the bit axis direction $\left(\delta=\frac{R O P}{N}\right)$. 


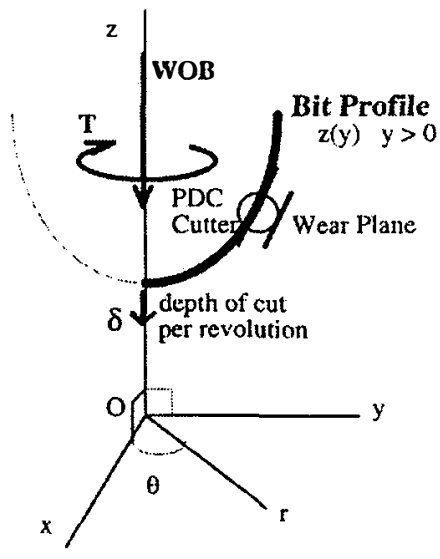

Figure 10: Schematic diagram of bit profile in meridian plane

\subsection{Statement of a wear law}

Describing wear evolution needs defining orientation of the wear flat, and the volumetric wear rate.

It is usually admitted that wear flat develops parallel to the wall of the rock e.g. practically tangent to the axisymmetric volume defined by the bit profile, which is supported by experimental evidence (Warren, ${ }^{11}$ ).

Volumetric wear law is usually proposed in the general form (Glowka, ${ }^{10}$ ):

$$
\frac{d V_{w}}{d l}=C^{*} \frac{F_{n}}{A_{w}^{m}} \text { with } 0 \leq m \leq 1
$$

Where $V_{w}$ is the volume of PDC cutter removed by wear, $l$ the linear displacement of the cutter on the rock surface, $F_{n}$ the total normal force applied to the cutter, $A_{w}$ the wear flat area, and $C^{*}$ a wear coefficient.

Instead of this global law, since it is possible to separate the forces on the cutter, it seems reasonable to postulate a more rational law in terms of thickness $\xi$ lost by wear on the cutter wear flat and shear stress $F_{t}^{f} / A_{w}$ applied on it, as follows:

$$
\frac{d \xi}{d l}=\frac{1}{C} \frac{F_{t}^{f}}{A_{w}}=\frac{\mu}{C} \frac{F_{n}^{f}}{A_{w}}
$$


This law is equivalent to (5) when setting $m=0$, and noticing that $d V_{w}=$ $A_{w} d \xi$

\subsection{Dip angle of cutter wear flats}

It now possible to precise angle $\alpha$ as a function of position of the cutter on bit profile and depth of penetration $\delta$, according to the hypothesis of wear flat parallel to bit profile (Figure 10):

$$
\sin \alpha=\vec{n} . \vec{\tau}=\frac{\delta}{\left(4 \pi^{2} y^{2}+\delta^{2}\right)\left(1+z^{\prime 2}\right)^{1 / 2}}
$$

$\vec{n}$ is the unit external normal to bit profile and $\vec{\tau}$ is the unit tangent to the helicodal trajectory of a cutter passing through the bit profile.

\section{Bit wear evolution}

Using expression (4), rate of wear expresses as:

$$
\frac{d \xi}{d l}=\frac{\mu}{C} \frac{F_{n}^{f}}{A_{w}}=\frac{\mu \sigma_{0}}{C}\left(1-\exp \left(-\alpha(\delta, y) / \alpha_{0}\right)\right)
$$

expressing distance increment $d l$ in terms of the rotational frequency $N$ gives finally :

$$
\frac{d \xi}{\left(2 \pi \mu N \sigma_{0} d t\right)}=y\left(1-\exp \left(-\alpha(\delta, y) / \alpha_{0}\right)\right)
$$

This equation appears as an intrinsic cutter wear rate, which is function of cutter position on bit profile. For a given rock, this quantity depends on the bit profile and on the bit penetration per revolution $\delta$, but not on the location and the number of cutters.

\section{Global forces on the bit}

Global forces result from local integration of local forces on cutters. With similar notations as for the single cutter, Torque and Weight On Bit write :

$$
(T)=(T)^{c}+(T)^{f} \text { and }(W)=(W)^{c}+(W)^{f}
$$


It is interesting to note with Detournay ${ }^{3}$, that the global cutting forces applied to the bit do not depend on bit geometry, provided the specific energy be supposed constant for all cutters :

$$
(T)^{c}=\frac{1}{2} \epsilon_{0} \delta R^{* 2} \text { and }(W O B)^{c}=\zeta \epsilon_{0} \delta R^{*}
$$

where $\left(\delta R^{*}\right)$ is the rock surface swept by the bit in one revolution in a meridian plane and $R^{*}$ radius of the "bit cutter line profile", defined by Detournay. ${ }^{3}$. Indeed, radius $R^{*}$, which includes existence of external cutters can be replaced by the profile radius $R_{b}$ with the maximal relative error of $\frac{d_{c}}{2 R_{b}}$. $(W)^{f}$ and $(T)^{f}$ result from summing up friction forces on cutters wear flats :

$$
(T)^{f}=\Sigma\left(y F_{\tau}^{f}\right) \text { and }(W)^{f}=\Sigma F_{n}^{f}
$$

The cutter friction forces can be expressed as :

$$
F_{n}^{f}=A_{w} f(\alpha) \text { and } F_{t}^{f}=\mu F_{n}^{f}
$$

where $A_{w}$ is the wear flat area, which shape is a truncated ellipse, given the cylindrical circular shape of the PDC cutter. This surface can be expressed in terms of the wear depth $\xi$ in the normal direction to the surface of the rock wall (5):

$$
\begin{array}{r}
A_{w}=\frac{d_{c}^{2}}{2 \sin \theta}\left(\frac{1}{2} \arccos \sqrt{\left.\left(1-4\left(\omega-\omega^{2}\right)\right)-\sqrt{(} \omega-9 \omega^{2}+8 \omega^{3}-4 \omega^{4}\right)}\right. \\
\omega=\frac{\xi}{d_{c} \cos \theta} \text { with } \theta, \text { rake angle, } d_{c}, \text { cutter diameter }
\end{array}
$$

$\xi$ is given from integration of (9)

\section{Illustrative examples}

For illustration, some simple bit geometries have been considered. Intrinsic wear distribution on the bit profile, according to equation (9), is given in Figure 11 for an elliptic bit profile $y^{2} / R^{2}+z^{2} / S^{2}=1$, with ellipticity $R / S=$ $0.57 ; 1 ; 1.74$ corresponding to elongated elliptic, circular, oblate elliptic profile and for two different bit penetretion $\delta$. Notice that for higher $\delta$, a higher wear rate occurs for external cutters, which is currently predicted by other models in literature (Glowka ${ }^{10}$ ). But for lower $\delta$, a reverse tendency can be noticed for the sharp elliptical profile. 


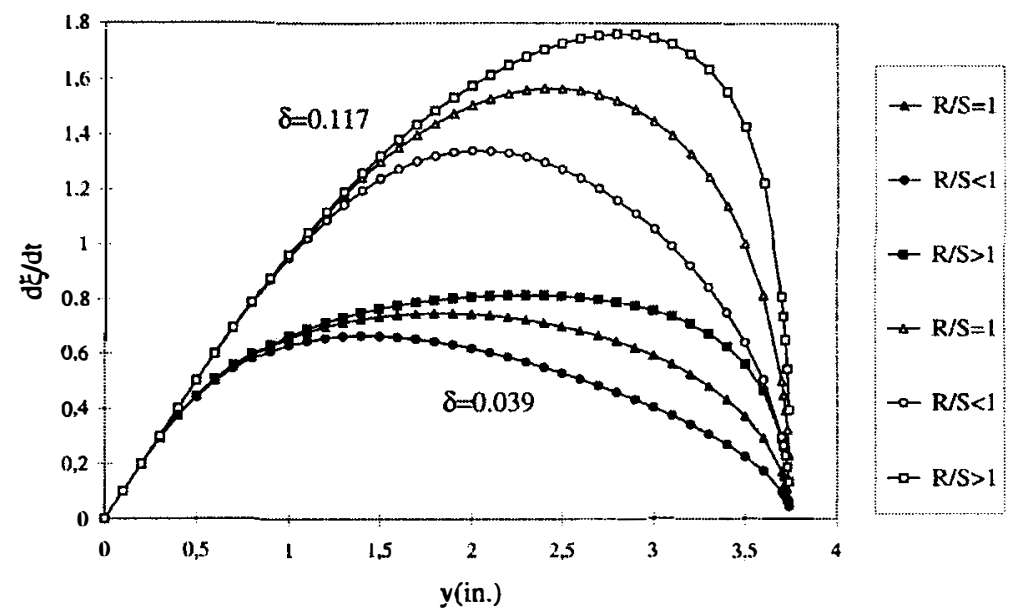

Figure 11: Intrinsic wear distribution on the bit profile

The model allows to find again some results observed on laboratory tests (Warren ${ }^{11}$, Glowka ${ }^{10}$ ). Wear flat effect results in the upward concave curve $T$ vs. $W O B$ (Figure 12), illustrating the better efficiency of the bit as $W O B$ increases, i.e., as depth of cut increases.

\section{Conclusion}

It can be considered that a reasonable understanding of mechanisms on the cutting edge and wear flat of a PDC cutter has been now achieved, so that a better modelling of PDC bit performance and better insight in wear laws can be expected. In this study, the elastoplastic nature of the frictional mechanism has been demonstrated, which expresses as a law relating the frictional stresses on wear flat contact to the movement of the bit, relatively to the rock wall.

A simplified law for this mechanism has been proposed, together with a reasonable wear law for the cutter wear flat. This has allowed to propose a PDC drill bit model which wear evolution is governed by the frictional mechanism which can be called abrasion. This model shows that wear evolution depends on the profile and on the depth of penetration per revolution. In this case, the cutter distribution on the bit has no influence with respect with the frictional wear, unless another wear law be envisaged with respect to the cutting effects.

The next step will be the validation and experimental identification of the 


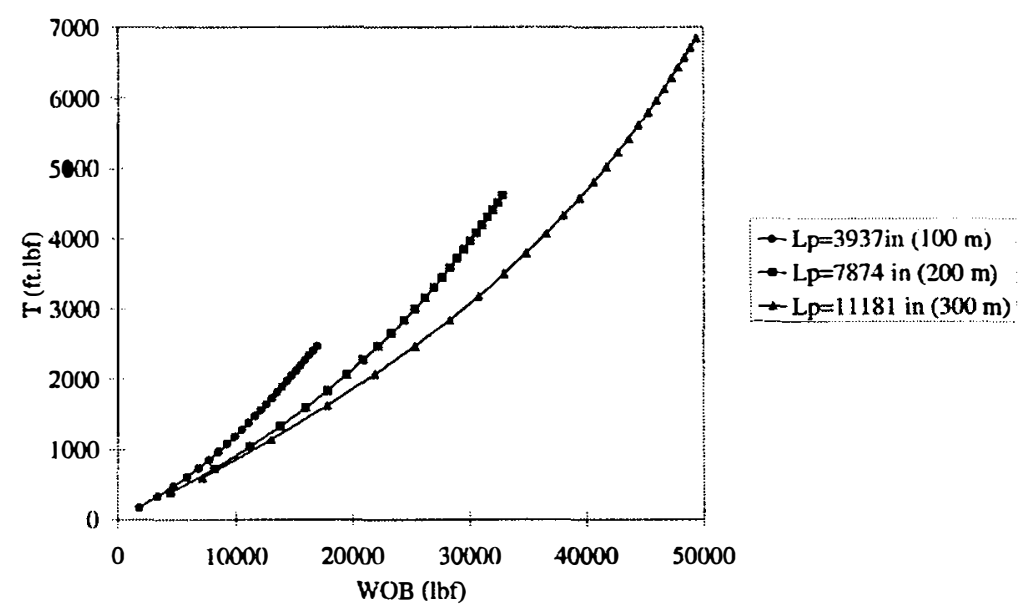

Figure 12: $T$ versus $W O B$

parameters of the model, which will finally allow for an optimisation of the geometry of the bit.

\section{References}

1. R. Feenstra, $S P E, 1988,675-684$.

2. D.A. Glowka, SPE 14222, 1985.

3. E. Detournay and P.Defourny, Int. J. Rock Mech. Min. Sci. and Geomech. Abstr., 29(1),13- 23,1992.

4. H. Sellami, PhD thesis, ENSMP, France, 1987.

5. E. Kuru, PhD thesis, Louisiana State Univ. Baton Rouge, La, 1990.

6. D. Nguyen, Minh, PhD thesis, Université de Paris VI, France, 1974.

7. H. Geoffroy, PhD thesis, Ecole Polytechnique, France, 1996.

8. J.I. Adachi, Master's thesis, University of Minnesota, USA, 1996.

9. M.H. Maitournam, PhD thesis, ENPC, France, 1989.

10. D.A. Glowka, Sandia Report 86-1475, Sandia national laboratories, 1987. 11. A. Sinor and T.M. Warren, SPE drilling Engineering 128-136, 1989. 